\title{
Sobre el Anteproyecto de Código Procesal Civil CHILENO DE 2006. UNA "INTERVENCIÓN PROVOCADA"*
}

\author{
MANUEL ORTELLS RAMOS**
}

RESUMEN: El autor hace un análisis global al Anteproyecto de Código Procesal Civil chileno, efectuando aportaciones y realizando algunas advertencias y criticas al prelegislador desde distintas perspectivas, entre ellas, la configuración constitucional del derecho fundamental de acceder a la Justicia; la comprensión de la relación jurídico-procesal y las facultades de las partes sobre el proceso; los limites de algunas potestades jurisdiccionales sobre la prueba, etc.

Palabras Clave: Proceso civil chileno - Derecho a la tutela judicial efectiva - Política Jurídica - Principios del proceso.

\section{Concerning the 2006 ChILEAN CIVIL Procedural Code DRAFT BILL. AN "INDUCED INTERVENTION"}

ABSTRACT: The author globally analyzes the draft bill of the Chilean Civil Procedural Code, contributing with some warnings and critiques to the pre-legislator from different perspectives. Among them we find the constitutional configuration of the fundamental right of access to Justice; the comprehension of the procedural-legal relationship and the faculties of the parts concerning the proceedings; the boundaries of some legal authorities concerning the evidence, etc.

KEY WORDS: Chilean civil process - right to the effective legal tutelage - Legal Policy - Principles of the proceedings.

Este artículo contiene, de manera más ordenada, completa y con algún aparato crítico -aunque no muy amplio- la intervención del autor en el seminario "El Derecho Procesal Chileno en el siglo XXI: tendencias actuales", organizado por la Universidad de los Andes y celebrado en Santiago de Chile, el 23 de septiembre de 2008. Está destinado a formar parte de una obra colectiva, que reuniría varias aportaciones que se presentaron en el evento académico mencionado, proyecto cuya realización sería, sin duda, útil para el debate del Anteproyecto de Código Procesal Civil chileno de 2006.

-. Catedrático de Derecho Procesal, Universitat de València (Estudi General), España. Correo electrónico: Manuel.Ortells@uv.es

Fecha de recepción: 18 de noviembre de 2008.

Fecha de aceptación: 22 de diciembre de 2008. 
SUMARIO: I. Preliminares. II. El límite constitucional: derecho de acceso a los tribunales y disposiciones generales de inadmisión por examen anticipado del fondo del asunto. III. Más acá de la constitucionalidad, pero en una zona "sensible" de las opciones de politica jurídica: los poderes del juez y las facultades de las partes respecto de la aportación de los hechos y respecto de su prueba. 1. Una opción clara en cuanto a la aportación de los hechos relevantes para la sentencia y una confusa propuesta de regulación sobre los poderes probatorios del juez y de las partes. 2. La tentación de cerrar en falso una opción de politica jurídica procesal muy polémica. Soluciones razonables de compromiso. IV. En un terreno politicamente más neutro: propuestas del ACPC/2006 orientadas a la eficacia, efectividad, eficiencia del proceso. 1. Oralidad del procedimiento. Agilización del procedimiento: contradicciones internas del ACPC/2006. A) ¿Oralidad para el proceso civil? ¿Cuánta oralidad o para qué la oralidad? Un procedimiento adecuadamente oral. B) Normas para la agilización del procedimiento: contradicciones internas del ACPC/2006. 2. Problemas con la efectividad de algunos nuevos instrumentos de la tutela ejecutiva

\section{PRELIMINARES}

Un determinado sistema procesal siempre está situado en un contexto sincrónico -el conjunto del ordenamiento a cuya realización jurisdiccional sirve- y en un contexto diacrónico -las tradiciones de interpretación, aplicación y práctica de la actividad procesal en el foro-, de modo que, a quien se acerca a ese sistema desde fuera, siempre le resulta difícil la comprensión y la valoración del mismo. En todo caso es una tarea a la que hay que enfrentarse con absoluta humildad.

Pero también es cierto que los textos normativos, o los antetextos -como ahora es el caso-, tienen en sí mismos un significado -a veces una falta de él- que es útil analizar para saber si el legislador, o el prelegislador -sobre todo si pretende ser innovador- ha diseñado las disposiciones adecuadas para alcanzar los fines que persigue.

Con esta finalidad se pueden hacer, en el texto o antetexto, algunas catas ilustrativas.

Esto es lo que me propongo hacer, en las páginas que siguen, respecto del Anteproyecto de Código Procesal Civil, según el texto que fue presentado el 6 de diciembre de 2006. En adelante, citaré ese texto como ACPC/2006 o como Anteproyecto, aunque advierto, también, que los artículos que mencionaré sin indicar el cuerpo legal al que pertenecen serán artículos de ese texto prelegislativo.

Además de reiterar la humildad con la que asumo esta intervención mía, debo justificarla. Principalmente, para quien piense que es una intervención de tercero. Mi intervención no es voluntaria -o espontánea, 
como prefiero decir-, pero tampoco estrictamente coactiva -terminología que, por lo demás, estimo inapropiada, porque alude más a obligación que a carga-. Es una intervención provocada. Y, por seguir con el símil procesal, por dos entidades que podemos considerar "partes": el Ministerio de Justicia de la República de Chile, que, en el número 7 de su Boletín Jurídico -correspondiente a noviembre de 2005-publicó una entrevista conmigo, en la que muchas preguntas versaban sobre las líneas generales de un futuro Código Procesal Civil; y la Universidad de los Andes, que me invitó a tratar el tema -ya con Anteproyecto en la mano- en el seminario "El Derecho Procesal Chileno en el siglo XXI: tendencias actuales", celebrado en Santiago, el 23 de septiembre de 2008.

Se comprenderá, pues, que no pueda callarme. Más aún: que no me haya callado. He hablado y escrito -y escribiré, ahora- con el esfuerzo de objetividad que me corresponde como académico, aunque también desde el afecto a ese gran país y a muchos colegas chilenos, con cuya amistad tengo la suerte de contar. Eso hace que el objeto de mis reflexiones no me sea del todo indiferente. Soy un tercero que quiere ser "parte".

\section{EL LÍMITE CONSTITUCIONAL: DERECHO DE ACCESO A LOS TRIBU- NALES Y DISPOSICIONES GENERALES DE INADMISIÓN POR EXAMEN ANTICIPADO DEL FONDO DEL ASUNTO}

Sin duda, la primera cata que debe hacerse en un proyecto legal debe perseguir la comprobación de si alguno de sus contenidos contrasta con los preceptos constitucionales, excede de los límites que estos fijan a la libertad de configuración normativa del legislador.

No es razonable pensar que esos excesos vayan a ser frecuentes, y, cuando en apariencia existen, probablemente una interpretación correctora para, precisamente, conformar la norma a Constitución, permitirá obviarlos. Pero es aconsejable detectarlos previamente a que el texto se convierta en ley; de ese modo se hacen innecesarias operaciones posteriores de "salvamento" de la constitucionalidad, cuyos resultados son a veces inciertos.

En nuestro caso quiero llamar la atención sobre determinadas disposiciones que podrían colisionar con el derecho a la tutela judicial, en cuanto derecho a obtener un pronunciamiento de un tribunal sobre un asunto litigioso, si se cumplen los requisitos procesales condicionantes de la admisibilidad.

Este derecho ha sido considerado por el Tribunal Constitucional español como parte del contenido fundamental del derecho a la tutela judicial efectiva, reconocido por el art. 24.1 de la Constitución Espa- 
ñola ${ }^{1}$. A la misma conclusión puede, sin duda, llegarse para Chile con base en el art. 19 de su Constitución Política -en cuanto reconoce que "La Constitución asegura a todas las personas: $\left.3^{\circ}\right)(\ldots)$ Toda sentencia de un órgano que ejerza jurisdicción debe fundarse en un proceso previo legalmente tramitado. Corresponderá al legislador establecer siempre las garantías de un procedimiento y una investigación racionales y justos"-, y en los artículos 10 de la Declaración Universal de los Derechos Humanos, 14.1 del Pacto Internacional de Derechos Civiles y Políticos y 8.1 de la Convención Americana sobre Derechos Humanos.

Las disposiciones del ACPC/2006 que han suscitado mi preocupación, por su potencialidad lesiva del derecho fundamental reseñado, son las que, en calidad de regla general -es decir, no acotada a tipos específicos de litigios-, atribuyen a los órganos jurisdiccionales potestades de inadmisión de la demanda in limine litis por manifiesta falta de fundamento -hay que entender: cualquier elemento de ese fundamento- (art. 27.1), o por manifiesta falta de legitimación -es decir: manifiesta falta del específico componente del fundamento que se refiere a la atribución subjetiva de la pretensión- (art. 248, párrafo segundo).

La razón esencial por la que estas disposiciones pueden ser cuestionadas es, por decirlo castizamente, que ponen el carro delante de los bueyes. Técnicamente: niegan la entrada en el proceso con base en el pronóstico de que la pretensión que se interpone no será considerada fundada, aunque alcanzan esta conclusión prescindiendo, precisamente, de las alegaciones, de las pruebas y de la contradicción a los que, generalmente, el ordenamiento somete la verificación del fundamento de las pretensiones. Si la racionalidad de este criterio de admisión es cuestionable cuando influye en la admisión de un recurso ${ }^{2}$, en mayor medida debe serlo cuando incide en la toma en consideración de una petición inicial de tutela judicial.

A la peligrosidad esencial que encierran las disposiciones mencionadas, vienen a ańadirse, en el ACPC/2006, otros elementos de imprecisión e inseguridad que agravan los inconvenientes.

1 Ortells Ramos, M. (1999) Introducción al Derecho Procesal. Granada: Comares, pp. 135141; más resumido en Ortells Ramos, M., Cámara Ruiz, J., Juan Sánchez, R. (2006) Derecho Procesal. Introducción. Madrid: Edisofer, pp. 210-215; con interesantes análisis, Borrajo Iniesta, I., Díez-Picazo Giménez, I., Fernández Farreres, G. (1995) El derecho a la tutela judicial y el recurso de amparo. Una reflexión sobre la jurisprudencia constitucional. Madrid: Civitas, pp. 25-93.

2 Para un supuesto de esta clase en Derecho espańol, véanse, por ejemplo, las críticas de DíEzPicazo y Ponce de León, L. (1993). "Prólogo", en Martínez-Calcerrada y Gómez, L. La nueva casación civil. Estudio de la Ley 10/1992, de 30 de abril, reforma de los procesos civiles. Madrid: Civitas, pp. 17-18; De la Oliva Santos, A. (1997). "Dictamen de urgencia sobre el "Anteproyecto de Ley de Medidas Urgentes de Reforma Procesal", en De la Oliva Santos (Coord.). Papeles del C.G.P.J. (1990-1996). Madrid, pp. 34, 58-59. 
En primer lugar, la sistemática del ACPC/2006 proyecta una gran imprecisión sobre el ámbito objetivo de aplicación de las mencionadas disposiciones. El art. 27, apartado 1 -que se encuentra bajo el epígrafe de "Principios básicos"- extiende la potestad de inadmisión a todo supuesto de manifiesta falta de fundamento. Pero al regular más específicamente las potestades del juez en el procedimiento, los arts. 248,258 y 259 únicamente se refieren a la falta manifiesta de legitimación, que es solo una parte de la manifiesta falta de fundamento. En efecto, no parece que el supuesto más general del art. 27 deba entenderse incluido en la mención que hace el art 248 a "otro defecto manifiesto que impida la existencia, validez o eficacia del proceso", porque el sentido de estas expresiones se halla más próximo a lo que serían presupuestos e impedimentos procesales o requisitos de validez de actos iniciales del proceso, y no a defectos de fundamento de la pretensión objeto del proceso. Lo que conduce a preguntarse si, en definitiva, la genérica facultad de inadmisión del art. 27 subsiste o ha quedado limitada al supuesto parcial de la falta manifiesta de legitimación.

En segundo lugar, el propio prelegislador revela su temor ante los excesos de esta norma y busca establecer una salvaguarda frente a los mismos disponiendo, en el art. 259, último párrafo, que la inadmisión por la causa considerada se producirá "solo en la medida en que el fundamento de la decisión se encontrare debidamente acreditado con los antecedentes existentes en el tribunal".

Pero esta salvaguarda dista de ser satisfactoria, por diversas razones:

$1^{a}$ Es imprecisa, porque existe contradicción en cuanto a si los antecedentes debidamente acreditativos han de resultar solo de la demanda -como parece exigir el art. 258, apartado 9)- o pueden resultar de antecedentes en general "existentes en el tribunal" -según dice el art. 259, último párrafo-, lo que permitiría a este último considerar, a estos efectos, incluso otros procesos pendientes ante él. Dejando aparte la gravedad de esta segunda opción, el problema es previo y consiste en la denunciada imprecisión.

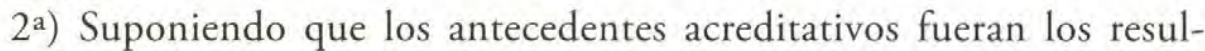
tantes de la propia demanda y de los documentos que existe la carga de acompañar a la misma (art. 243), la salvaguarda que examinamos significaría, en todo caso, que una parte del fundamento de la pretensión (el referido a su atribución subjetiva) solo puede ser probado mediante documentos y no con los demás medios de prueba que el ordenamiento establece, en general, como admisibles. En definitiva, una injustificada restricción del derecho a la prueba.

$3^{\text {a) }}$ En fin, es posible que la justificación de la norma de inadmisión por enjuiciamiento anticipado de parte del fundamento de la pretensión sea diferente al que hasta ahora hemos considerado. Por ejemplo, este: 
presuponiendo que los hechos sean ciertos -por lo tanto, presupuesto el éxito de toda la prueba respecto de los mismos- el Derecho nunca ampararía una consecuencia jurídica como la que el actor pretende, o -si hubiera que limitarse a los supuestos de carencia manifiesta de legitimaciónen favor del actor que la pretende, o en contra del demandado frente al que es pretendida. Prescindiendo de que, en sí, ya es merecedor de crítica que el texto ofrezca oportunidad para dudar sobre la justificación de una norma cuya aplicación genera consecuencias tan graves, la justificación apuntada no legitima la generalidad con la que esa norma es concebida. Una cosa es que, en supuestos específicos en los que sea claro que, a pesar de la certeza de los hechos, la consecuencia jurídica pretendida por el actor nunca tiene amparo normativo, el legislador pueda, especialmente, negar la admisión de la demanda ${ }^{3}$, y otra muy diferente generalizar esta justificación, lo que conduce a negar que, de modo general, el debate procesal pueda alumbrar significados de las normas jurídicas o contenidos de principios jurídicos que respalden las consecuencias jurídicas pretendidas por el actor.

Por lo demás, la norma que consideramos -tanto en su alcance más amplio, como en el más restringido al aspecto de la legitimación- me parece poco realista. Atendidas las molestias y los costes que comporta la actividad procesal, resultan estadísticamente poco significativos los casos en que alguien inicie una actividad procesal con absoluta carencia de fundamento. En mi opinión, se hace de un caso de libro una norma legal, que, además, crea más problemas que los que resuelve.

\section{Más ACÁ de la CONSTITUCIONALIDAD, PERO EN UNA ZONA "SEN- SIBLE” DE LAS OPCIONES DE POLÍTICA JURÍDICA: LOS PODERES DEL JUEZ Y LAS FACULTADES DE LAS PARTES RESPECTO DE LA APORTA- CIÓN DE LOS HECHOS Y RESPECTO DE SU PRUEBA}

En mis sintéticas respuestas a una entrevista que mencioné poco antes ${ }^{4}$, me expresaba a favor de la radicación constitucional del principio dispositivo, como rector de la tutela jurisdiccional de las situaciones jurídicas de Derecho privado, pero también de la autonomía relativa que respecto del principio mencionado tienen otros principios rectores de la atribución de poderes al juez y de facultades a las partes en el proceso civil. no admitir a trámite una demanda en la que se pretenda el cumplimiento, en forma específica, de la promesa de esponsales.

4 Boletin Juridico del Ministerio de Justicia (2005). Gobierno de Chile, año 4, número 7, noviembre, pp. $42-43$.
} 
Conviene desarrollar un poco más lo que allí quedó apuntado, antes de examinar las propuestas del ACPC/2006 acerca de la ordenación de los poderes del juez y de las facultades de las partes respecto de la prueba.

La actuación de aquel sector del ordenamiento que reconoce a los particulares un ámbito de autonomía jurídica en el que, dentro de ciertos límites, libremente ejercen y disponen de sus derechos y, con idéntica libertad, configuran sus relaciones jurídicas, queda coherentemente entregada a la libre voluntad de los propios particulares. De ella depende la iniciación del proceso, la configuración de su objeto -a la que el juez está vinculado por el deber de congruencia- y la propia terminación del proceso, mediante actos de disposición condicionantes del sentido de la resolución judicial. Los principios de oportunidad y dispositivo derivan así de la naturaleza privada del Derecho material que se aplica, con una intensidad tal que ha hecho decir a JAUERnig que no son más que "el aspecto procesal de la autonomía privada" 5 , y a CARNACINI que el principio dispositivo ni es procesal, ni genéricamente un principio autónomo, sino que con él se alude a la disponibilidad de la tutela jurídica por el interesado, que simboliza el elemento característico e inconfundible del derecho subjetivo ${ }^{6}$.

Un cambio esencial de dichos principios solo sería posible desde una supresión de la categoría del derecho subjetivo y de la autonomía de la voluntad en las relaciones jurídicas privadas ${ }^{7}$, que se hallaría en abierta contradicción con el modelo socioeconómico establecido por la Constitución Política de la República de Chile. Me parecen, en este aspecto, básicos los derechos que reconocen los apartados $21^{\circ}, 23^{\circ}$ y $24^{\circ}$ del artículo 19 de la Constitución.

Sin embargo, como también puso de manifiesto Carnacini, es necesario distinguir lo que afecta al régimen de la tutela de interés material en el proceso -ámbito propio del principio dispositivo-y lo que, por el contrario, atañe al régimen interno del instrumento procesal ${ }^{8}$. Esta distinción conduce a la conclusión de que el monopolio de la parte en la instrucción del proceso no constituye una consecuencia inevitable del otro monopolio, aquel por el cual los órganos jurisdiccionales solo resuelven previa demanda de parte. Por otro lado, el estudio de Liebman en el que el fundamento del principio de aportación se traslada del carácter disponible de los derechos en juego, a la tutela de la imparcialidad del juzgador, ha

JAUERNIG, O. (1981) Zivilprozessrecht, München, p. 66.

Carnacini, T. (1951). "Tutela giurisdizionale e tecnica del processo". Studi in onore di Enrico Redenti nel XL anno del suo insegnamento, II, Milano, p. 752.

Capelletti, M. (1973). El proceso civil en el Derecho comparado. Trad. Sentís Melendo. Buenos Aires, pp. 3-39.

8 Carnacini (1951) passim. 
puesto particularmente en claro la autonomía de este principio respecto a la naturaleza del Derecho material ${ }^{9}$.

$\mathrm{La}$ interpretación del principio de aportación en el sentido de un poder de disposición, conduce de entrada a una afirmación absurda: las partes tendrían una facultad de disposición sobre los hechos. ¿Pero es que acaso los hechos son algún elemento patrimonial sometido al poder de disposición de su titular? ¿Acaso puede hablarse de una titularidad de los hechos? Se comprende que los hechos existan o no, que se afirmen, se oculten o se nieguen, pero no, en cambio, que se disponga de ellos ${ }^{10}$.

Además ¿qué significa el principio de aportación interpretado como manifestación del poder de disposición?: Que las partes, con su actividad de alegación y de prueba, ponen al juez en la ineludible situación de dictar una determinada sentencia. Ahora bien, esta consecuencia no solo no ańade nada a los efectos que las partes pueden producir realizando los actos de disposición típicos (renuncia, allanamiento y transacción), sino que parece además un camino sospechoso para conseguir los efectos de los actos de disposición.

La extensión del poder de disposición que tienen las partes sobre la relación jurídica material privada a la relación jurídica procesal, con las consecuencias de ser necesaria la instancia de aquellas para impulsar el proceso iniciado, para que el juez pueda constatar la falta de presupuestos procesales o los vicios que pueden afectar a algunos actos, no solo carece de fundamento dogmático en la naturaleza del Derecho material que debe aplicarse, sino que es inconsecuente con la concepción dogmática del proceso como relación jurídica de Derecho público ${ }^{11}$.

Respecto al mantenimiento de la valoración legal de algunos medios de prueba, una cosa es decir que solo resulta compatible con relaciones jurídico-materiales de carácter privado ${ }^{12}$ y otra distinta que sea una consecuencia lógica y dogmática de la naturaleza de aquellas relaciones. Que ambas cuestiones están situadas en planos distintos se demuestra con solo pensar que negar valor probatorio legal a la documentación de un negocio jurídico, ni es negar la libertad negocial (arts. 658, 1255 ambos del Código Civil español), ni el valor vinculante de las consecuencias de su ejercicio (art. 1258 del Código Civil español). Como con relación al principio de aportación, puede decirse que el de valoración legal de la prueba, interpretado como manifestación del poder de disposición, nada añade a

Liebman, E. T. (1960). "Fondamento del principio dispositivo", Rivista di Diritto Processuale, pp. 551-565.

10

11

12

Bomsdorf, F. (1970). Prozessmaximen und Rechtswirklichkeit. Berlin, p. 279.

BüLow, O. (1964). La teoría de las excepciones y de los presupuestos procesales, Trad. Rosas Lichtschein, Buenos Aires, pp. 287-302.

Furno, C. (1954). La teoría de la prueba legal. Trad. González Collado. Madrid, pp. 154155; Jiménez Conde, F. (1978). La apreciación de la prueba legal y su impugnación. Salamanca, pp. 63-69. 
la eficacia que este último alcanza a través de los actos típicos en que se manifiesta.

\section{Una opción clara en cuanto a la aportación de los hechos relevan- tes para la sentencia y una confusa propuesta de regulación sobre los poderes probatorios del juez y de las partes}

Nada que objetar en cuanto a su contenido -aunque la forma de expresión podría mejorarse- sobre la opción del ACPC/2006 por la primera de las manifestaciones del principio de aportación de parte: el juez solo podrá fundar su sentencia en los hechos alegados -introducidos, aportados al proceso- por las partes ${ }^{13}$.

Entiendo que esta opción se manifiesta, en primer término, en varias disposiciones del ACPC/2006 que imponen que exista una previsión en norma expresa para que el tribunal pueda pronunciarse de oficio sobre excepciones (arts. 5, 27.2 y 4), llamadas, en otras disposiciones, defensas y contestaciones (arts. 168, 169, 261 y 268, a).

En segundo término, en la disposición del art. 195, que, al establecer el deber de congruencia, determina que el pronunciamiento en cuanto al mérito no puede "extenderse a puntos no expresamente sometidos a juicio por las partes, salvo en cuanto las leyes manden o permitan a los tribunales proceder de oficio" (art. 195) ${ }^{14}$.

Por el contrario, en cuanto a la atribución de poderes al juez y de facultades a las partes sobre la iniciativa probatoria y sobre la amplitud del examen con ocasión de la práctica del medio de prueba correspondiente, la opción del ACPC/2006 no solo me parece menos definida, sino decididamente confusa, porque se expresa en dos grupos de normas cuyos contenidos son antitéticos.

En efecto, parece que unas manos hayan escrito (que una mente haya pensado) el contenido del art. 27, en algunos de cuyos apartados el juez aparece investido de unos poderes probatorios fuertes.

Entiendo que ese es contenido del principio de aportación de parte y no del principio dispositivo, siempre que no se trate de aquellos hechos que, por ser identificadores de la causa de pedir, delimitan la pretensión procesal, el objeto de proceso, que queda sujeto -durante la tramitación- a los límites de la litispendencia, y, concluido el proceso por sentencia firme, a la cosa juzgada: Ortells Ramos (1999) 204; Ortells Ramos, M., con otros autores (2008). Derecho Procesal Civil. Cizur Menor: Thomson-Aranzadi, pp. 252-259, 322-324.

Estimo que, en defecto de otras más directas, las disposiciones citadas en los dos últimos párrafos del texto permiten fundar la conclusión de la limitación a los hechos alegados por las partes. En efecto, presupuesta la vigencia del principio iura novit curia, que confiere al tribunal el poder-deber de establecer qué normas y principios jurídicos son aplicables, atendidos -y respetados- la pretensión del actor y los hechos alegados por las partes, los "puntos" -en general, o, especialmente, los que favorecen al demandado- limitativos de la potestad de enjuiciamiento han de ser -dejando aparte las pretensión procesal que sea objeto del proceso- las alegaciones de hecho que proporcionan la base para la aplicación de normas favorables a una o a otra parte. 
Por ejemplo, el apartado 4), que apodera al tribunal para "Ordenar las diligencias necesarias al esclarecimiento de la verdad de los hechos controvertidos, respetando el derecho de defensa de las partes, en la oportunidad establecida en la ley". La duda que se le plantea al intérprete -y que, según lo que veremos después, se acrecentará- es la de si -atendido que el artículo 27 se sitúa en un contexto de disposiciones con un contenido más general y básico- resultará necesaria una norma legal más específica para que lo que se prevé en ese apartado sea un deber efectivo para el juez o bastará con lo que ese apartado dice para entender que el juez ya tiene la potestad (el poder-deber) de acordar de oficio aquellas diligencias.

Otro ejemplo, el del apartado 5) del mismo artículo 27, según el cual el tribunal podrá "Disponer en cualquier momento, durante la audiencia de juicio, la presencia de los testigos, de los peritos y de las partes, para requerirles las explicaciones que estime necesarias al objeto del pleito". En el contexto de los medios de prueba practicados -a instancia de parte, ¿también de oficio?- la duda es, ahora, si el objeto de las explicaciones que el tribunal puede requerir deberá limitarse a una finalidad de aclaración de lo manifestado por el sujeto de prueba o podrán versar directamente sobre los hechos relevantes para la decisión sobre el objeto del proceso, en el caso de que las declaraciones iniciales de los sujetos de prueba no se hayan referido a aspectos de aquellos hechos.

Por el contrario, otras manos, otras mentes, parecen estar detrás de los artículos que, de modo más específico, rigen lo qué condiciona la admisión de los concretos medios de prueba, así como la intervención del tribunal en la práctica de los mismos.

Así, el art. 278 deja claro que el tribunal no podrá decretar diligencia alguna de prueba. Expresión clara de la regla general de la iniciativa de parte para la admisión de las pruebas, aunque tal vez demasiado drástica si se tiene en cuenta que, después, el propio ACPC/2006 establece excepciones en favor del acuerdo de oficio de la inspección judicial -art. 316-y de la reproducción de hechos -art. 318-.

Por otro lado, el mismo artículo 278 y el art. 315 limitan la intervención activa del tribunal dentro de la práctica de la prueba a las preguntas destinadas a obtener aclaraciones, aunque el art. 315 también habla de adiciones.

El Anteproyecto se comporta como aquella gallina que cacareaba en un lugar y ponía los huevos en otro: en la parte de su texto en la que formula normas con cierto estilo de principios, el ACPC/2006 opta por los poderes oficiales del juez sobre los medios de prueba a practicar y sobre el alcance de su intervención en la práctica; en cambio, en la parte del texto que regula más específica y detalladamente la admisión y práctica de los medios de prueba, el ACPC/2006 se inclina por reconocer, como regla, el monopolio de las partes, aunque con excepciones para medios de prueba determinados. 
El resultado es perturbador, tanto más cuanto que, incluso en el contexto del segundo bloque de preceptos, aparecen normas como la del art. 324, in fine, según la cual "Al final (scilicet: de la práctica de la prueba propuesta por las partes y practicada en el orden fijado por ellas) se rendirá la prueba que pudiere ordenar el juez". Es legítimo dudar del significado de esta norma, colocada en un contexto tan oscuro: ¿Significa solo una regulación del momento en que deberá ser practicada la prueba ordenada de oficio por el juez, cuando esté habilitado para ordenarla según las normas más específicas que hemos mencionado hace poco? O, además de lo anterior ¿Es una confirmación de los poderes probatorios oficiales de carácter general que se le confieren, básicamente, en el art. 27?

\section{La tentación de cerrar en falso una opción de política jurídica procesal muy polémica. Soluciones razonables de compromiso}

Tengo la impresión de que el panorama tan confuso que presenta el ACPC/2006 se explica por la reticencia a definir con precisión la opción sobre la atribución o no al juez de poderes oficiales respecto de la práctica de la prueba y sobre la medida de esa atribución. A su vez, esa reticencia puede encontrar explicación en que quienes han elaborado el texto de Anteproyecto son conscientes de que esa opción ha sido y sigue siendo polémica.

Sin lugar a dudas es una polémica muy justificada, porque en la misma se hallan involucradas, de un lado, la cuestión de cuál es el mejor modo de realizar el Derecho en los casos concretos, siempre sobre la base de una petición determinada de tutela de una persona que se afirma titular de un derecho subjetivo o interés jurídico privado -este condicionante no se discute; o, al menos, quiero dejar claro que yo no lo pongo en duda-, y, por otro lado, la imparcialidad como componente esencial de la jurisdicción.

No voy, ahora ${ }^{15}$, a terciar en la polémica ${ }^{16}$. Sí que diré, no obstante, que el debate ganaría en objetividad y en utilidad para perfeccionar los instrumentos destinados a constatar los hechos concretos relevantes en el proceso de declaración, si se abandonaran las soflamas ideológicas -sobre todo las que se ocultan so capa de exposición "ante los mortales" de una

15 Mis humildes reflexiones sobre esta polémica -entrar a fondo en la misma, hay que dejárselo a los colosos que ya ocupan el terreno-, que aparecen en este artículo en diferentes momentos, están en OrTells Ramos (1999) 149-153, 201-211, que sustancialmente reflejan el contenido de la memoria sobre los temas básicos del Derecho Procesal, que preparé para mi oposición a cátedra de 1984; resumidamente en OrTells Ramos, en OrTells/Cámara/ JUAN (2006) 242-244, 286-291.

16 Sirve para conocer los principales términos de la misma, porque, dejando aparte la posición del autor, ofrece una información completa y actualizada, EtXeBerRía GuRIDI, J. F. (2003). Las facultades judiciales en materia probatoria en la LEC. Valencia: Tirant lo Blanch, passim. 
especie de "verdades reveladas"- y las actitudes más propias de hooligans, y se potenciaran análisis con métodos científicos -no jurídicos, sino empíricos, en el contexto de la psicología y de la sociología- acerca de la adquisición del conocimiento sobre los hechos en los procesos judiciales y sus implicaciones sobre la función del juez y las situaciones procesales de las partes.

En cualquier caso, es evidente que la actitud del ACPC/2006 frente a la polémica no es la más aconsejable: satisfacer a tirios y a troyanos es no satisfacer a unos, ni a otros. O peor: es abandonar la realización efectiva de la opción problemática a la práctica judicial, cuya inevitable dispersión pondrá en peligro la igualdad en la aplicación de la ley -no solo la de la ley procesal, sino la de las leyes todas, que necesitan del proceso para ser aplicadas- ${ }^{17}$; o acabará por dejar la opción en manos de la Corte Suprema, con abandono de la responsabilidad del legislador acerca de una cuestión a la que, hoy por hoy, se le asigna calado político.

Distinto a dejar la cuestión en el terreno de la indefinición, es buscar soluciones de compromiso, aceptables para quienes sostienen posiciones discrepantes, coherentes con la preservación de la imparcialidad judicial, también con una ordenación principalmente orientada a estimular la responsabilidad y la diligencia de las partes, y que hallen formulación en disposiciones lo suficientemente precisas para contrarrestar riesgos de arbitrariedad judicial ${ }^{18}$.

En esta línea, pueden apuntarse algunas sugerencias:

1a) Podría defenderse la potestad de oficio para acordar aquellos medios de prueba que no se destinan a comprobar la concurrencia o no de hechos, sino a complementar la capacidad de enjuiciamiento del juez cuando las reglas o parámetros a los que las normas remiten no son jurídicos, sino reglas de la sana crítica, reglas del criterio humano, cuyo conocimiento y/o aplicación a hechos concretos requiere conocimientos especializados. Me refiero a la prueba pericial, cuya naturaleza de medio de prueba, en la que estaría implícito el ser un medio a disposición de las partes, ha sido puesta en cuestión desde posiciones nada sospechosas de una ideología que persiga dinamitar una opción sustancialmente liberal

17 Remito a las antiguas, pero no por eso menos iluminadoras, palabras de BAur, F. (1965), "Potere giudiziale e formalismo del Diritto processuale". Rivista Trimestrale di Diritto e Procedura Civile. pp. 1683-1696: la regulación legal del proceso, delimitando los poderes del juez y de las partes, sirve para que el Derecho material pueda tener, a través del proceso, una aplicación igual en los caos iguales.

18 Acerca de esta exigencia de técnica legislativa sobre la atribución de las potestades de dirección a los jueces, me permito remitir a mi prólogo a la monografía de TAVOLARI Goycoolea, P. (2004). El abuso en el proceso. Santiago: Editorial Congreso, pp. 12-16. 
respecto de la distribución de los poderes y facultades en la realización de la prueba ${ }^{19}$.

$2^{\text {a) }}$ Acuerdo de oficio e intervención de oficio en la práctica de medios acordados a propuesta de parte, considero que pueden defenderse sin riesgo de quiebra de la imparcialidad en los supuestos en que el juez persigue la aclaración del significado de la información que ha sido introducida por el medio de prueba practicado a propuesta de parte o la obtención de elementos de juicio que le permitan valorar la credibilidad o fiabilidad de esos medios.

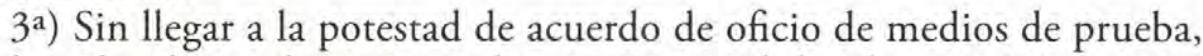
al tribunal se le puede encomendar una potestad de advertencia a las partes acerca de medios de prueba que no hayan propuesto, que pueden ser pertinentes y necesarios para la carga probatoria que les incumbe -atendidos los hechos que han quedado controvertidos-y que, en definitiva, las partes serán libres de proponer o no.

Es el modelo al que responde el artículo 429.1, párrafo segundo de la LEC espańola de 2000, según el cual:

"Cuando el tribunal considere que las pruebas propuestas por las partes pudieran resultar insuficientes para el esclarecimiento de los hechos controvertidos lo pondrá de manifiesto a las partes indicando el hecho o hechos que, a su juicio, podrían verse afectados por la insuficiencia probatoria. Al efectuar esta manifestación, el tribunal, ciñéndose a los elementos probatorios cuya existencia resulte de los autos, podrá señalar también la prueba o pruebas cuya práctica considere conveniente.

En el caso a que se refiere el párrafo anterior, las partes podrán completar o modificar sus proposiciones de prueba a la vista de lo manifestado por el tribunal".

Esta potestad no quiebra la imparcialidad del juzgador porque en su régimen está ínsito poder ser ejercitada a favor de cualquiera de las partes procesales cuya proposición probatoria haya resultado a primera vista deficitaria. Es una potestad a ejercitar con imparcialidad, cualidad exigible del juez no solo al sentenciar sobre el objeto del proceso, sino también en el ejercicio de los poderes de dirección procesal.

Aunque con una dificultad técnica difícilmente superable en cuanto a algunos medios de prueba ${ }^{20}$, esta potestad del juzgador permite que este

19 Una información básica sobre las orientaciones doctrinales que consideran al perito más como un auxiliar del juez, que como sujeto de un medio de prueba, y sobre los ordenamientos que establecen regulaciones coherentes con esas orientaciones, Font Serra, E. (2000). El dictamen de peritos y el reconocimiento judicial en el proceso civil. Madrid: Editorial La Ley, pp. 32-37; Garciandía González, P. M. (1999). La peritación como medio de prueba en el proceso civil español, Pamplona: Aranzadi, pp. 74-76.

20 Me refiero al interrogatorio de las partes y a la testifical, cuya proposición inicial no requiere hacer constar cuál será su objeto específico, que solo será conocido con la formulación de las preguntas. 
haga una aplicación prospectiva de las reglas de la carga de la prueba en el concreto asunto litigioso y en una etapa de su tratamiento procesal en la que las partes todavía pueden reaccionar útilmente, complementando sus proposiciones probatorias iniciales ${ }^{21}$. Esta potestad judicial de advertencia a las partes no es desconocida en el ACPC/2006, que, en su artículo 14, la prevé para los supuestos en que el tribunal estima que debe resolver los problemas de carga de la prueba no con arreglo a las reglas legales, especiales o generales, sino en función de la concreta facilidad probatoria que tenga alguna de las partes.

4a) En fin, tampoco incurren en ningún exceso en los poderes de realización de oficio de medios de prueba, con riesgo de pérdida de la imparcialidad por beneficiar unilateralmente a alguna de las partes, que haya sido negligente en el ejercicio de sus facultades de proposición e intervención en la práctica de las pruebas, las normas que autorizan al tribunal a acordar de oficio lo necesario para la práctica de medios de prueba que no pudieron practicarse -en términos absolutos o de un modo pleno- en el tiempo ordinario de práctica, sin que la imposibilidad fuera imputable a la parte que los propuso. En este aspecto, el régimen de las diligencias finales en Derecho español es injustificadamente rígido, porque solo permite que se proceda de oficio en el supuesto del apartado 2 del art. 435 de la LEC española de $2000^{22}$, y no en el de la regla $2^{\text {a }}$ del apartado 1 del artículo $^{23}$. Téngase presente que la idea de que, en estos dos supuestos, el juez está procediendo de oficio, no se ajusta a la realidad: la parte propuso el medio de prueba y prestó la colaboración legalmente requerida para su práctica; si, ante el fracaso en la práctica, el tribunal acuerda lo necesario para hacerla posible in extremis, no hace más que corresponder a aquella actividad procesal de la parte, superando obstáculos que esta no tiene por qué soportar.

Ortells Ramos con otros autores (2008) 355.

"Excepcionalmente, el tribunal podrá acordar, de oficio o a instancia de parte, que se practiquen de nuevo pruebas sobre hechos relevantes, oportunamente alegados, si los actos de prueba anteriores no hubieran resultado conducentes a causa de circunstancias ya desaparecidas e independientes de la voluntad y diligencia de las partes, siempre que existan motivos fundados para creer que las nuevas actuaciones permitirán adquirir certeza sobre aquellos hechos.

En este caso, en el auto en que se acuerde la práctica de las diligencias habrán de expresarse detalladamente aquellas circunstancias y motivos".

"1. Solo a instancia de parte podrá el tribunal acordar, mediante auto, como diligencias finales, la práctica de actuaciones de prueba, conforme a las siguientes reglas: (...)

$2^{\text {a }}$ Cuando, por causas ajenas a la parte que la hubiese propuesto, no se hubiese practicado alguna de las pruebas admitidas". 


\section{EN UN TERRENO POLÍTICAMENTE MÁS NEUTRO: PROPUESTAS DEL ACPC/2006 ORIENTADAS A LA EFICACIA, EFECTIVIDAD, EFICIEN- CIA DEL PROCESO}

El último gran apartado de este somero examen del ACPC/2006 se centra en unas cuestiones políticamente más neutras, en el sentido de que, desde ningún planteamiento de política jurídica, se renuncia a buscar las mejores soluciones para lograr la eficacia, efectividad o eficiencia -sé que los significados de estos términos no son los mismos, pero prescindamos ahora de intentos de aclaración-del proceso civil.

El problema de la eficacia, efectividad o eficiencia del proceso, de la tutela jurisdiccional que se pretende a través del mismo y que ha de ser dada en él, es multiforme en sus manifestaciones -involucra el acierto de la sentencia, la evitación de dilaciones indebidas, que la tutela en su caso concedida sea real, práctica, de verdad satisfactiva- y también en los instrumentos idóneos para darle una solución idónea - diseño adecuado del procedimiento (tal vez, de los procedimientos) para la tutela declarativa; protección de la eventual concesión de esa tutela mediante una tutela cautelar apta para contrarrestar todos los riesgos de inefectividad; instrumentos ejecutivos suficientes para realizar una tutela de condena ya concedida).

Mis observaciones se limitarán a dos aspectos de ese panorama tan vasto y se centrarán, obviamente, en las concretas propuestas del ACPC/2006:

$\left.1^{\circ}\right)$ Instrumentos generales mediante los que pretende lograrse la efectividad de la que podemos llamar tutela declarativa común.

$2^{\circ}$ ) Una valoración de la efectividad de algunos instrumentos de la tutela ejecutiva.

\section{Oralidad del procedimiento. Agilización del procedimiento: con- tradicciones internas del ACPC/2006}

Los dos temas de este apartado son relativamente independientes, salvo la incidencia que pueden tener normas importantes para el segundo tema sobre la concentración, que es uno de los componentes estructurales de un procedimiento oral. Aquí no examinaremos esa incidencia, pero trataremos de los dos temas, porque en ambos se manifiestan las opciones más generales del ACPC/2006 destinadas a conseguir la eficacia, efectividad, eficiencia del proceso de declaración.

\section{1. ¿ ¿ Oralidad para el proceso civil? ¿Cuánta oralidad o para qué la oralidad? Un procedimiento adecuadamente oral}

Obviamente, el tipo de procedimiento -entendiendo por tal la forma de expresión de los actos procesales y el modo de ordenarlos en la serie 
procedimental- era, y es, una de las principales preocupaciones a la hora de configurar el nuevo proceso civil chileno.

Es oportuno, de entrada, que recuerde las preguntas y mis respuestas sobre este particular, en la entrevista que he mencionado antes ${ }^{24}$.

“Es posible - se preguntaba- la existencia de procedimientos de oralidad absoluta en el ámbito civil? ¿Cuáles serían los límites a dicha oralidad?".

Respondí entonces y sigo pensando ahora que:

"A la primera parte de la pregunta la respuesta es: oralidad absoluta, absolutamente no. Y no solo en el ámbito civil.

En cuanto a la segunda parte, yo no me plantearía los límites de la oralidad, como si esta forma procedimental debiera ser una regla general, a cuyo alcance, tendencialmente omnicomprensivo, hubiera que poner coto.

En mi opinión, la cuestión de la forma de la actividad procesal no es una cuestión de exclusividad de formas, sino de combinación de estas, consistente en someter cada clase de acto o de conjuntos de actos a la forma que resulte más idónea para que cada acto o conjuntos de actos cumplan la función que les corresponde. Y para la última valoración mencionada (forma idónea para cumplir la función), se han de tener presentes criterios muy diferenciados. Ha de dotarse de seguridad y fijeza a la proposición del objeto del proceso y a la formulación de las alegaciones básicas del actor y del demandado y ha de garantizarse a la parte contraria una razonable posibilidad de reacción; en mi opinión estos criterios imponen el requisito de la escritura para los actos de demanda y de contestación. Pero también han de evitarse dilaciones indebidas en el proceso, lo que conduce a que las aclaraciones y las modificaciones que la ley permita realizar en los actos iniciales del proceso recién mencionados deban realizarse oralmente, para no dar lugar a pérdidas de tiempo con nuevos intercambios de actos escritos. Y también es esencial que la prueba sea producida ante el juez en la forma que le permita hacer una valoración más correcta de la misma, y esto de nuevo impone la oralidad, al menos para la práctica de algunas clases de medios de prueba, como son el interrogatorio de las partes - libre de las rigideces de la confesión-, la declaración de testigos y la prueba pericial en cuanto a la exposición del dictamen y examen contradictorio de los peritos por las partes".

Esta opinión nada tiene de original. Es solo la conclusión razonable que puede extraerse de la observación del uso combinado de la oralidad y la escritura que se hace en los procesos civiles técnicamente más cuida$\operatorname{dos}^{25}$. 
El prelegislador chileno ha optado por un procedimiento adecuadamente oral, como opción de carácter más general entre las varias que se dirigen a dotar de eficacia, efectividad, eficiencia, al proceso (civil) de declaración.

No entraré, porque no es tema del ACPC/2006 y porque a nadie se le escapa, en que el funcionamiento real de un modelo procedimental como el elegido depende de unos medios personales, organizativos y materiales adecuados -en lo cuantitativo y lo cualitativo- a la carga de trabajo que esté previsto que los tribunales deberán soportar y al modo en que ese trabajo ha de ser asumido en un procedimiento de las características del que diseña el ACPC/2006.

Me voy a limitar a unas observaciones sobre el diseńo normativo del procedimiento, que, de entrada y en general, merece una buena valoración.

En algunos aspectos, las previsiones propias de un procedimiento adecuadamente oral son mejores que algunas regulaciones del procedimiento de la LEC espańola de 2000 -que, siguiendo el imperativo del art. 120.2 de la Constitución Espańola, también se ha inclinado por una combinación adecuada de oralidad y escritura- ${ }^{26}$.

Me parecen representativas de esa mayor perfección técnica:

10) El tratamiento oral de la reposición de resoluciones de dirección procesal que no pongan fin al proceso y se hayan dictado durante una audiencia ${ }^{27}$. La LEC espańola de 2000 solo establece este régimen de reposición, que es el adecuado al contexto de oralidad en el que se dicta la resolución recurrible, para unos supuestos especiales, mientras que la regla general permite -salvo que las partes consientan la resolución en el actoque esta sea dictada, notificada y recurrida por escrito al concluir la sesión oral en la que haya sido inicialmente pronunciada ${ }^{28}$.

$2^{\circ}$ ) La forma escrita del ofrecimiento de las pruebas testimonial y pericial (arts. 244 y 263), frente a la proposición oral en la audiencia previa o en la vista del juicio verbal, que se dispone en los artículos 429.1 y 443.4 de la LEC española de 2000 , y que acaba convirtiéndose en un

F./ Ortells, M. Editores (2008). Oralidad y escritura en un proceso civil eficiente/Oral and Written Proceedings: Efficiency in Civil Procedure, dos volúmenes, Valencia: Universitat de València, passim.

26 Para una apreciación general de esa combinación de formas, Ortells Ramos, M. (2000). "Der neue spanische Zivilprozess. Leitlinien der Ley de Enjuiciamiento Civil vom 7. Januar 2000". Zeitschrift für Zivilprozess International, 5 Band, pp. 102-103.

27 Recuérdese que el art. 342 dispone: "La reposición de las resoluciones pronunciadas durante audiencias orales deberá promoverse tan pronto se dictaren y solo serán admisibles cuando no hubieren sido precedidas de debate. La tramitación se efectuará verbalmente, de inmediato, y de la misma manera se pronunciará el fallo". 
ejercicio de dictado de los abogados al secretario judicial, que es una muestra de oralidad no solo inútil, sino inconveniente.

Por el contrario, otras previsiones del ACPC/2006 incurren, unas, en excesos de oralidad, mientras que otras son poco conciliables con esa forma procedimental.

Ocurre, en mi opinión, lo primero con el régimen de la sentencia in voce. El ACPC/2006 ha establecido la emisión oral e inmediata de la sentencia como regla general. Recuérdese el art. 327: "Una vez concluido el debate en la audiencia de juicio, el juez comunicará de inmediato su resolución, indicando someramente los principales fundamentos tomados en consideración para adoptarla. Excepcionalmente, cuando la audiencia de juicio se hubiere prolongado por más de dos días, o recayere sobre un punto de derecho de complejidad, cuya concurrencia fundamentará, podrá postergar la decisión del caso hasta el quinto día hábil, lo que se indicará a las partes al término de la audiencia, fijándose de inmediato el día en que la decisión será comunicada". Es cierto que se establecen excepciones, alguna de ellas - la segunda- tan genérica que puede conducir a que, en la realidad, la regla general acabe siendo la contraria a la de la ley. Pero ese es un cabo que no es prudente dejar suelto. Sugeriría una solución contraria: regla general, sentencia por escrito, en breve plazo desde la conclusión del juicio; excepciones legalmente tasadas y para supuestos que razonablemente puedan considerarse de sencilla resolución, de sentencia oral inmediata.

Lo segundo -es decir, soluciones poco conciliables con la oralidadme parece encontrarlo en el régimen de la vista en apelación.

En primer término, la valoración que puede hacerse de la "relación de la causa" (art. 361, párrafo primero) es ambivalente: por un lado, satisface las exigencias de la oralidad como vehículo de la publicidad -entendida como posibilidad de conocimiento por terceros de los términos del litigio-; por otro, aparenta una especie de mediación de segundo grado, difícilmente justificable en cuanto al conocimiento por los ministros de los materiales que han accedido al pleito por escrito.

En segundo término, es incoherente con la oralidad la admisión, aunque sea a posteriori, de las minutas de los alegatos (art. 361, párrafo séptimo). El estado de las cuestiones litigiosas puede ser más complejo al terminar la prueba en la primera instancia y, sin duda, son menores en esa circunstancia las posibilidades de una preparación reflexiva de una exposición de las mismas por los abogados, sin que estas razones conduzcan al art. 326 a autorizar la presentación de una nota escrita de conclusiones, después de su exposición oral. Tampoco justifica la admisión de las minutas de los alegatos la finalidad de que haya constancia segura de los contenidos de tales actos, porque, al menos la parte apelante (principal o adhesiva) ha contado con la posibilidad de interposición por escrito del recurso, incluidas sus peticiones y fundamentos (arts. 349 y 356, párrafo tercero). 


\subsection{Normas para la agilización del procedimiento: contradicciones internas del ACPC/2006}

La eficacia, efectividad, eficiencia, de la tutela judicial declarativa resultan, sin duda, favorecidas, al menos en el aspecto de la celeridad o agilidad del pronunciamiento sobre la tutela pretendida, si el procedimiento es desembarazado de incidencias en general, o, especialmente, de las que pueden consistir en alteraciones de los hechos relevantes aportados al proceso en las etapas procedimentales ordinariamente previstas y en la proposición y práctica de medios de prueba también fuera de esas etapas.

En esta materia el ACPC/2006 contiene algunas previsiones merecedoras de consideración y que conducen a conclusiones muy diferentes, que nos sitúan, a veces, en el desconcierto y la estupefacción.

\section{a) La severidad respecto de la admisión de hechos y de medios de prueba fuera de las oportunidades procesales ordinarias}

El ACPC/2006 opta por una orientación muy rigurosa en cuanto a las excepciones a la preclusión de alegaciones de hechos y de proposiciones de medios de prueba, que no se hubieran presentado en las oportunidades procesales ordinariamente previstas.

El art. 247 solo admite la alegación, fuera de la demanda y de la contestación, de hechos nuevos, en el sentido de acaecidos después de la contestación y hasta la conclusión de la causa. No prevé -o yo no las he descubierto- excepciones a favor de hechos preexistentes, aunque desconocidos por la parte y descubiertos después de las posibilidades ordinarias de alegación, ni siquiera rodeando estas excepciones con las prevenciones necesarias para evitar el fraude de ley ${ }^{29}$.

El Anteproyecto es igualmente severo con la admisión de proposiciones extemporáneas de medios de prueba: aparte de los que tengan por objeto - para el actor- hechos alegados en la contestación y de la prueba de hechos nuevos (arts. 245, 263, párrafo cuarto), solo admite las pruebas sobrevivientes (art. 245) o supervinientes (art. 263, párrafo cuarto). Entiendo que estos adjetivos significan pruebas cuya fuente ${ }^{30}$ ha surgido con posterioridad al tiempo ordinario de proposición, pero no aquellas cuyas fuentes preexistían a ese tiempo, aunque eran desconocidas para la parte, que las ha descubierto después ${ }^{31}$.

29 Para el régimen de estas excepciones a la preclusión de la alegación de hechos en Derecho espańol, OrTelis Ramos, con otros autores (2008) 336-337, 516.

30 Para el concepto de fuente de prueba, siguiendo a Sentís Melendo, Ortells Ramos, con otros autores (2008) 353-354.

31 Para el tratamiento de estas excepciones a la preclusión para proponer prueba, la LEC espańola de 2000 distingue dos clases de medios de prueba. De un lado, la prueba documental y 
En mi opinión, debería reconsiderarse la conveniencia de mantener este acentuado rigor, atendiendo a una faceta de la eficacia (efectividad, eficiencia) de la tutela judicial declarativa que sería cínico marginar, cual es la de mejorar las probabilidades de acierto y justicia de la sentencia; pero incluso considerando el aspecto más aparente de aquellas cualidades de la tutela judicial, es decir, la más ágil y rápida resolución sobre la misma.

Es cierto que un proceso en el que no se admitan nuevos materiales (hechos, medios de prueba), incluso en supuestos en que admitirlos podría tener justificación, se desarrollará y terminará más rápidamente, pero esa restricción, o bien permitirá poner en cuestión el grado de acierto y justicia de la sentencia dictada (si ya no es admisible hacer valer esas novedades en un proceso posterior, por impedirlo la cosa juzgada), o bien conducirá a que lo que se expulsó por la ventana del "primer" proceso -para agilizarlo-, acabe entrando por la puerta abierta de un proceso nuevo, que contribuirá al aumento del conjunto de la carga de trabajo del sistema judicial e influirá negativamente en que este pueda atender con mayor agilidad al conjunto de asuntos que penden ante él.

Un aspecto especial del rigor en la admisión extemporánea de medios de prueba es el de la inadmisión de medios de prueba en apelación/ segunda instancia (arts. 337, párrafo tercero, y 357). No son admisibles ni siquiera en el supuesto de que se trate de medios de prueba cuya admisión hubiera sido indebidamente rechazada en la primera instancia. Este supuesto, de indudable injusticia procesal, es tratado por el Anteproyecto de otro modo: constituye un motivo de nulidad (art. 366, h), que puede acumularse a la apelación (arts. 364 y 369) o, diciéndolo mejor, se tiene la carga de acumular a la misma (por el art. 370, que impone agotar las posibilidades de reclamación frente a vicios procesales). Esta técnica, que no permite al tribunal de la segunda instancia practicar la prueba indebidamente inadmitida, sino solo declarar una nulidad por ese vicio procesal, aboca, en mi opinión, a dos salidas inconvenientes: o los tribunales de segunda instancia tenderán, con facilidad, a declarar la nulidad, con sus antieconómicas consecuencias, o, para evitar esto, se orientarán hacia una interpretación restrictiva de la causal de nulidad del art. 366, h), exigiendo, para entenderla concurrente, requisitos adicionales de especial trascendencia de la prueba omitida, con lo que, en definitiva, se restringe, en realidad el derecho a la prueba.

mediante otros instrumentos materiales cuyo contenido sea informativo de hechos relevantes para el proceso; para estos medios admite la aportación excepcionalmente extemporánea, tanto por estricta novedad, como por anterior desconocimiento; OrTells Ramos, con otros autores (2008) 294-296, 519-520. Para los demás medios de prueba no prevé excepciones, por ninguna de las dos causas. 


\section{b) La sorprendente tolerancia con los incidentes innominados}

En neto y sorprendente contraste con la severidad mostrada en el tratamiento de las cuestiones que acabamos de examinar -que, en definitiva, son incidentes especiales-, el ACPC/2006 es ampliamente generoso y tolerante con los que podemos denominar "incidentes innominados". Esta opción no me parece coherente con el objetivo de agilizar, de imprimir rapidez al proceso, que se manifiesta en otras previsiones del Anteproyecto.

Veamos los rasgos generales del régimen de los "incidentes innominados":

10) Empieza llamando la atención la delimitación amplia, escasamente preocupada por una acotación precisa, y menos aún restrictiva, de lo que debe entenderse por "incidente": "toda cuestión accesoria al asunto principal" (art. 123) o, con base en una elemental interpretación a contrario del art. 125, cuestión que tenga "alguna" conexión con aquel asunto ${ }^{32}$.

$\left.2^{\circ}\right)$ Es cierto que, como regla general, el planteamiento del incidente no suspende el procedimiento principal, pero, según el art. 125, no solo la ley puede establecer especial efecto suspensivo, sino que el juez está habilitado para establecerlo en atención a un concepto jurídico indeterminado.

$\left.3^{\circ}\right)$ Pero, aunque el efecto suspensivo no se generalice, es lo cierto que la admisión tan generosa de incidentes -que podrán ser resueltos en diferentes sentidos- deja el procedimiento principal expuesto a un riesgo indefinido de "dinamitado", de alteración de su desarrollo.

$\left.4^{\circ}\right)$ Obviamente, el prelegislador es consciente de los riesgos apuntados y procura ponerles coto con las medidas de multas, consignaciones y depósitos previstas en el art. 127. No obstante, la técnica de, digamos, "control del abuso de incidentes" que establece esta disposición, lejos de resolver el problema, lo agrava, añadiendo a unas posibilidades demasiado amplias de alteración del desarrollo ordinario del procedimiento principal, la desigualdad de las oportunidades de aprovechar esas posibilidades, porque la oportunidad efectiva depende completamente de la capacidad económica de la parte. En síntesis: solo la parte que pueda pagarse el lujo, podrá "bombardear" a voluntad el desarrollo ordinario del procedimiento ${ }^{33}$.

Ni siquiera se utiliza la (probablemente inútil) fórmula restrictiva del art. 387 de la LEC española de 2000 , que requiere que "guarden... relación inmediata".

33 Llamo incidentalmente la atención sobre que este es el modo de tratamiento en el Anteproyecto de las conductas contrarias a la buena fe procesal: estas son consideradas conductas ilícitas (y sancionables con multas) y no como conductas procesalmente inválidas (y, por tanto, generadoras de actos inadmisibles en virtud de una cláusula general). No reproduciré aquí el art 8 del ACPC/2006, pero aconsejo leerlo y contrastarlo con el art. 11 de la Ley Orgánica del Poder Judicial española, según el cual: "1. En todo tipo de procedimiento se res- 


\section{Problemas con la efectividad de algunos nuevos instrumentos de la tutela ejecutiva}

Entro, ya para terminar, en la valoración de la efectividad de algunos instrumentos de la tutela ejecutiva, que el Anteproyecto ha introducido, pienso que con una fidelidad, quizá excesiva, a la LEC espańola de 2000. Me refiero a las multas -en algunos artículos incluso llamadas coercitivas, como en LEC española de 2000 (art. 505) - y, específicamente, al destino de las mismas y a los supuestos de su aplicación ${ }^{34}$.

Claramente, y más en el ACPC/2006 (art. 239) que en la LEC espańola de 2000, el acreedor de las multas es el tesoro público. Esto conduce a que deba plantearse el problema de la respectiva preferencia del crédito por las multas y del crédito que definitivamente -en caso de no haberse conseguido la ejecución en forma específica- se liquide como importe del equivalente dinerario de la prestación incumplida. Ambos créditos han de hacerse efectivos sobre el patrimonio del ejecutado y es posible que este no sea suficiente o, simplemente, que el completo descubrimiento de los activos patrimoniales ofrezca dificultades incluso para la satisfacción del crédito del ejecutante.

Es imprescindible establecer una norma expresa para esta situación. La ley española no lo hace. Tampoco la he visto en el ACPC/2006, pero no sé si puede entenderse establecida por una interpretación sistemática para la que a mí me faltan datos. Lo cierto es que una aplicación del régimen general puede tener consecuencias injustas.

Sería extremadamente grave que pudiera concluirse que, bajo determinadas circunstancias, el crédito por las multas coercitivas puede llegar a ostentar preferencia jurídico-material frente al crédito del ejecutante. Cualquier interpretación conducente a esta conclusión sería abiertamente contraria al derecho a la tutela judicial efectiva del ejecutante y a la función de las multas en la ejecución. Si las multas se han establecido como medio para la mayor efectividad de la tutela judicial ejecutiva, carecería de sentido que, de un lado, no hubieran contribuido a que se cumpla la prestación según la impone el título ejecutivo, y, de otro, impidan total o

petarán las reglas de la buena fe. (...) 2. Los Juzgados y Tribunales rechazarán fundadamente las peticiones, incidentes y excepciones que se formulen con manifiesto abuso de derecho o entrañen fraude de ley o procesal".

Sobre esta materia, más ampliamente, remito a Ortells Ramos, M. (2003). "Zwangsgeld oder Astreintes? Schwakende Lösungen im neuen spanischen Zwangsvollstreckungsrecht". Zeitschrift für Zivilprozess International, 8 Band, pp. 201-228. En castellano: OrTells RAmos, M. (2004). “¿Multas o astricciones? Una indefinición de la nueva ejecución forzosa”, Revista Internauta de Práctica Juridica, http://www.ripj.com, número 13, en-jun; y, especialmente sobre los supuestos en que pueden ser aplicadas las multas coercitivas, ORTELLS RAMOs, con otros autores (2008) 878-900. 
parcialmente la satisfacción del ejecutante mediante la obstaculización de la ejecución dineraria subsidiaria.

Sería una consecuencia menos grave, pero también injustificable, la de arrojar sobre el ejecutante, en alguna circunstancia, la carga de hacer valer, en una tercería de mejor derecho, la prioridad de su crédito respecto del crédito por las multas cuya ejecución hubiera alcanzado a causar un embargo anterior.

Pero, en fin, si por esta defectuosa configuración, los tribunales acabaran por retraerse a la hora de aplicar las multas, tampoco habría motivos para darse por satisfecho, porque es lo cierto que, bien diseńados, los medios de coerción indirectos, a disposición del tribunal de la ejecución, son una técnica muy útil, a veces imprescindible, para la efectividad de la ejecución de títulos con ciertas clases de prestaciones.

Por ejemplo, para las de hacer personalísimo (como ha previsto la LEC española de 2000 y también el ACPC/2006), y también para las prestaciones de no hacer, de omitir o abstenerse.

Precisamente respecto de su aplicación a la ejecución por prestaciones de la última clase mencionada surgen nuevos problemas con el régimen previsto para las multas, tanto en la LEC española de 2000, como en el ACPC/2006.

Al igual que el art. 710 LEC espańola de 2000, el Anteproyecto dispone la aplicación de multas coercitivas para forzar que se deshaga lo indebidamente hecho (art. 504, párrafo segundo), mientras que olvida disponer su aplicación para desincentivar la reiteración de incumplimientos de la conducta omisiva, en los casos en que el deber de abstención que el título ejecutivo impone tenga continuidad y, consiguientemente, pueda ser reiteradamente incumplido (por ejemplo, abstención de actos lesivos de una marca, de una patente, de conductas de competencia desleal en una relación específica). El art. 504, párrafo primero del Anteproyecto hace solo referencia a la advertencia de persecución penal, cuando hubiera sido más adecuado y útil imponer el pago de multas (u otra medida coercitiva dineraria) cada vez que se cometiera una nueva infracción del título. Así se ha acabado por hacer, en Derecho español, aunque con alcance sectorial (Ley de Marcas, en la que, además, el acreedor de la suma de dinero pasa a serlo el ejecutante; ejecución de condenas de cesación de conductas contrarias a intereses colectivos y difusos de consumidores y usuarios).

\section{BIBLIOGRAFÍA}

- Baur, F. (1965), "Potere giudiziale e formalismo del Diritto processuale". Rivista Trimestrale di Diritto e Procedura Civile.

- Boletín Jurídico del Ministerio de Justicia (2005). Gobierno de Chile, ańo 4 , número 7 , noviembre. 
- Bomsdorf, F. (1970). Prozessmaximen und Rechtswirklichkeit. Berlin.

- Borrajo Iniesta, I., Díez-Picazo Giménez, I., Fernández FaRRERES, G. (1995) El derecho a la tutela judicial y el recurso de amparo. Una reflexión sobre la jurisprudencia constitucional. Madrid: Civitas.

- Bülow, O. (1964). La teoría de las excepciones y de los presupuestos procesales, Trad. Rosas Lichtschein, Buenos Aires.

- Carnacini, T. (1951). "Tutela giurisdizionale e tecnica del processo". Studi in onore di Enrico Redenti nel XL anno del suo insegnamento, II, Milano.

- Carpi, F./ Ortells, M. Editores (2008). Oralidad y escritura en un proceso civil eficiente/Oral and Written Proceedings: Efficiency in Civil Procedure, dos volúmenes, Valencia: Universitat de València.

- Capelletti, M. (1973). El proceso civil en el Derecho comparado. Trad. Sentís Melendo. Buenos Aires.

- De la Oliva Santos, A. (1997). "Dictamen de urgencia sobre el "Anteproyecto de Ley de Medidas Urgentes de Reforma Procesal", en De la Oliva Santos (Coord.). Papeles del C.G.P.J. (1990-1996). Madrid.

- Díez-Picazo y Ponce de León, L. (1993). "Prólogo", en Martínez-Calcerrada y Gómez, L. La nueva casación civil. Estudio de la Ley 10/1992, de 30 de abril, reforma de los procesos civiles. Madrid: Civitas.

- Etxeberría Guridi, J. F. (2003). Las facultades judiciales en materia probatoria en la LEC. Valencia: Tirant lo Blanch.

- Font Serra, E. (2000). El dictamen de peritos y el reconocimiento judicial en el proceso civil. Madrid: Editorial La Ley.

- Furno, C. (1954). La teoría de la prueba legal. Trad. González Collado. Madrid.

- Garciandía González, P. M. (1999). La peritación como medio de prueba en el proceso civil español, Pamplona: Aranzadi.

- Jauernig, O. (1981) Zivilprozessrecht, München.

- Jiménez Conde, F. (1978). La apreciación de la prueba legal y su impugnación. Salamanca.

- Liebman, E. T. (1960). "Fondamento del principio dispositivo". Rivista di Diritto Processuale.

- Ortells Ramos, M. (1999) Introducción al Derecho Procesal. Granada: Comares.

- Ortells Ramos, M. (2000). "Der neue spanische Zivilprozess. Leitlinien der Ley de Enjuiciamiento Civil vom 7. Januar 2000”. Zeitschrift für Zivilprozess International, 5 Band.

- Ortells Ramos, M. (2003). "Zwangsgeld oder Astreintes? Schwakende Lösungen im neuen spanischen Zwangsvollstreckungsrecht". Zeitschrift für Zivilprozess International, 8 Band, pp. 201-228. 
En castellano: Ortells Ramos, M. (2004). “¿Multas o astricciones? Una indefinición de la nueva ejecución forzosa”, Revista Internauta de Práctica Jurídica, http://www.ripj.com, número 13, en-jun.

- Ortells Ramos, M., Cámara Ruiz, J., Juan Sánchez, R. (2006) Derecho Procesal. Introducción. Madrid: Edisofer.

- Ortells Ramos, M., con otros autores (2008). Derecho Procesal Civil. Cizur Menor: Thomson-Aranzadi.

- Tavolari Goycoolea, P. (2004). El abuso en el proceso. Santiago: Editorial Congreso, pp. 12-16. 
